\title{
A Single-stage, Continuous High Efficiency Extraction Device (HEED) for Flow Synthesis
}

\author{
Craig Day, Alejandro Saldarriaga, Michael Tilley, Howard Hunter, Michael G. Organ*, and \\ Derek J. Wilson*
}

Supporting Information 
Figure S1

A

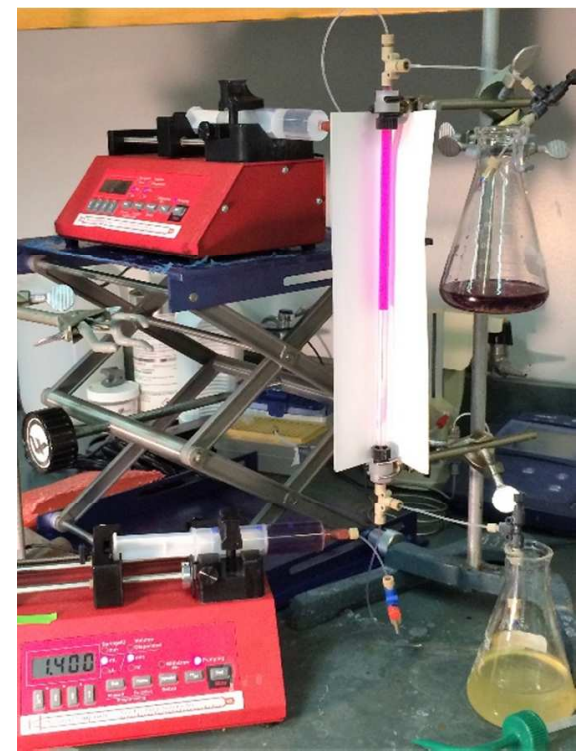

C

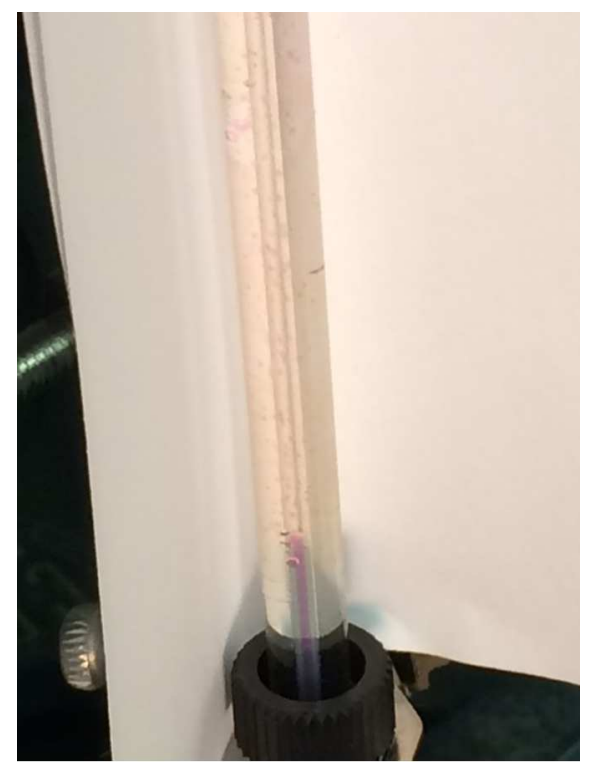

B

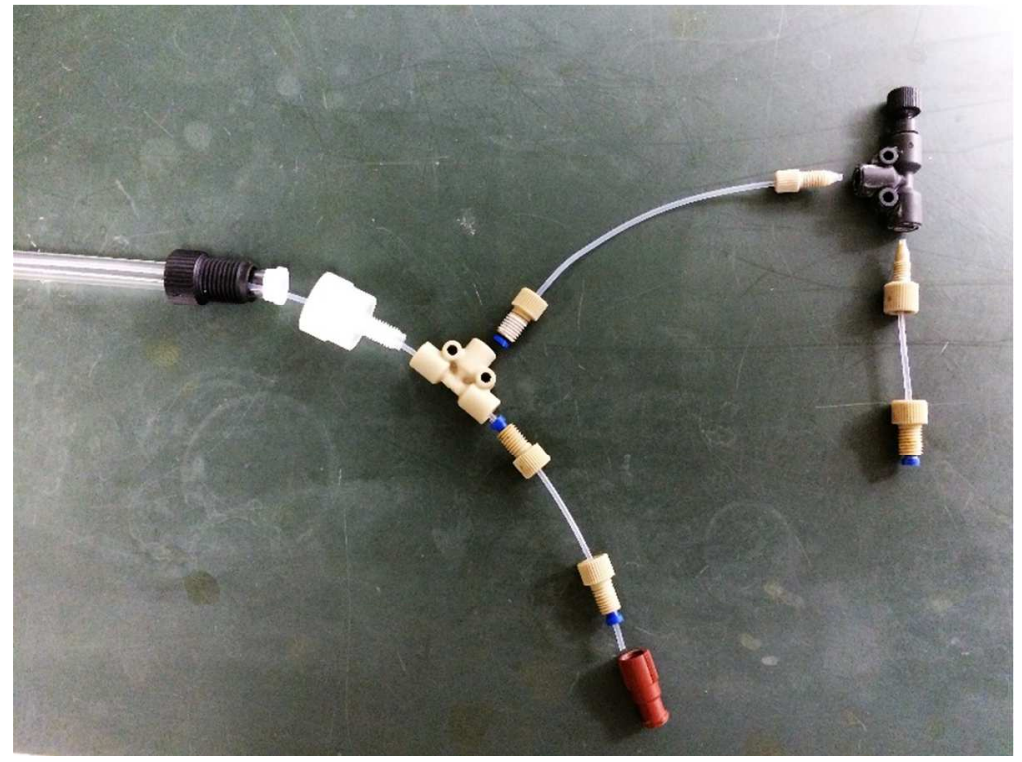

Figure S1. Additional photographs of the device. (A) The setup with high contrast interface. (B) Connectors assembly. (C) A closeup of the device in operation using potassium iodide as a water soluble dye. There is insufficient contrast to image the microstreams traversing the organic reservoir (which are emitted from, $150 \mu \mathrm{m}$ holes located at the end of the central 'purple' region near the bottom of the image). 